\title{
Podwalking: A framework for assimilating mobile methods into action research
}

Dr Simon P. Hammond. Norwich Medical School, University of East Anglia, Norwich. NR4 7TJ. United Kingdom. Tel: (+44) (0)1603 591460 Fax: (+44) (0) 1603 593552

Email: s.hammond@uea.ac.uk

Dr Neil J Cooper. School of Psychology, University of East Anglia, Norwich. NR4 7TJ. United Kingdom. Tel: (+44) (0)1603 59 2996, Fax: (+44) (0) 1603593552 Email:

Neil.Cooper@uea.ac.uk

Contributors:

Dr Simon $\mathrm{P}$ Hammond is the Programme Manager and Research Fellow in Qualitative Methods on the National Institute for Health Research (UK) funded "PERFECTED" research programme. He works collaboratively with vulnerable populations using a range of traditional and innovative qualitative methods to research patients' and professionals' experience of health care, life narratives and the applications of life story work.

Dr Neil $\mathrm{J}$ Cooper is a Charted Psychologist and Senior Lecturer in Psychology at UEA. His scholarly work orients around qualitative approaches in psychology and has involved in practice research concerning child protection, family support, life story work 


\begin{abstract}
This article brings together action research and mobile methods to demonstrate how the processes and assumptions which underpin participatory inquiry may be open to critical consideration. The concept of the 'podwalk', a phased mobile method, is introduced within a project oriented around the development of digital life story work with adolescents living in state care. Adopting an interactive researcher stance in relation to the discursive analysis of material gathered as the research unfolded, we demonstrate that a phased method can frame the entry and exit from the field and that mobile methods can provide a basis for illuminating the research process, especially the way in which power and participation are negotiated.
\end{abstract}

Keywords: mobile methods, digital technology, discourse analysis, adolescents, participatory action research, digital media 
PODWALKING

\section{Podwalking: A framework for assimilating mobile methods into action} research

This article presents an analysis of an action research process using mobile technologies within the context of a mobile methodology. Mobile digital technologies are so much part of our everyday environment that they are rapidly becoming ubiquitous. As Weiser (1991: p. 94) has noted "The most profound technologies....weave themselves into the fabric of everyday life until they are indistinguishable from it." Innovations which appeared revolutionary such as the integration of cameras into mobile phones have become so familiar that they are relatively unnoticed. Such technology can provide especially useful additions to qualitative data gathering and offer opportunities for the documentation of everyday experiences. Using this technological availability as its starting point, the article introduces Podwalking. Podwalking is an approach to planning, creating, editing and producing participant generated audio-visual journeys around places of personal significance. We introduce this approach and the framework that it provides in order to illustrate how mobile methods, situated within the plan, act, observe and reflect cycles of action research, can render ongoing critical reflections open to analysis. The amalgamation of mobile methods and action research in the podwalking framework allows the research process to be open to the same empirical inquiry as the products of research.

The article begins by providing a brief synopsis of how digital technologies have become part of the research process and then goes on to consider this within the analytical sphere of the interactive researcher. The context of a project using podwalking is then introduced along with its methodological framework. The 
PODWALKING

discursive analysis of material that was gathered as the project unfolded is used to illustrate how the podwalking framework can provide a basis for ongoing critical reflection over the course of the research process. Thus, we will show how this method can be used to illuminate the way in which power and participation are negotiated. We also show how a phased method such as this can structure the entry and exit to the field by providing a framework for negotiating research roles and enabling participants and researchers to conclude their involvement with tangible resources.

\section{The turn to mobilities and the interactive researcher}

Coinciding with the development of mobile technology has been the rise within the social sciences of what Büscher and Urry (2009) describe as the mobilities turn. This mobilities paradigm argues against the analysis of social life from assumptions of stability, and advocates an approach that takes into account the complexities of the fluid movements of people, objects and information. The focus of much mobilities research orients around migration, transport, tourism and other social actions. Quantitative research exploits mobile technology, because it may incorporate elements such as logfiles, and location tracking which are amenable to the statistical analysis of interactions and network developments. From a qualitative orientation the increased availability of mobile digital technology also includes the psychosocial exploration of place making, the way in which people are spatially attached, embedded in social networks, and how individuals “...construct emotional geographies..." (Sheller \& Urry, 2006: p. 216). The motilities paradigm has fostered the emergence of a range of techniques in which researchers move with participants (Ross, Renold, Holland, \& Hillman, 2009). Mobile methods such as bimbles 
PODWALKING

(Anderson, 2004), walking with video (Pink, 2007) and guided walks (Ross et al., 2009) all propose that walking around the physical environment with participants is less restrictive and yields data unlikely to be produced in conventional face-to-face interviews which are a routine strategy for generating qualitative data (Holstein \& Gubrium, 2003).

In exploring the quality of the research interview, Roulston (2010) draws attention to how different approaches to interviews demand quality criteria which correspond to their inherent assumptions about the function of the interview in the research process. In relation to postmodern researchers, employing a postmodern conception of interviewing which assumes that interpretative findings are situated, temporary and incomplete, Roulston (2010: p.220) suggests that:

Rather than achieving comprehensive descriptions of the phenomenon of investigation, researchers attempt to open up spaces for new ways of thinking, being, and doing... judgments about the quality of the work are in large part determined by readers and audience members...

The use of widely available of digital technology within mobile methods means that various elements of the wider research process can now be visible and open to scrutiny, indeed processes such as the researcher-participant relationship are open to analysis in the same way as interview material. This means that mobile researchers are able to consider the quality of the research process not only in relation to their 'interviews' but also can explore how quality may be demonstrated through material gathered within the wider research process. 
PODWALKING

In discursive psychology, the use of naturally occurring data, able to pass what Potter (2002) calls the dead researcher test, has become a preferred alternative to the interview. This test invites scholars to consider what would happen if they were to expire on the way to collect data. For a traditional interview, the event would not occur, while naturally occurring occasions would still go ahead with the researcher's demise inconsequential. In working with what Potter (2002) refers to as natural data, the presence of the researcher at the point of data gathering is erased, although their presence remains central in establishing the focus of an investigation and analysis.

O'Rouke and Pitt (2007) suggest that the dead researcher position means that analytical claims developed from data would lack incidental insight. This term refers to the contextual information about interview conversations that being there offers the researcher when they are involved in interviewing. They propose an alternative to the dead researcher in the form of an interactive researcher. O'Rouke and Pitt (2007) state that as a consequence of researcher involvement there is a doubling effect where the analyst acts twice, once as interpreter participating in the interaction and again during the analysis. Though subjectivity may have doubled, “...one might also say that the opportunity for the researcher to explore the discourse has also doubled." (O’Rouke \& Pitt, 2007: Para 18). By stepping inside the inquiry process, researchers may 'muddy' data collection and analysis. However by paying attention to discursive practices in interviews researchers can clearly evidence specific research strategies which link to analytical assertions such as claims to the empowerment of participants through giving them a voice. By exploring positioning processes in interviews researchers enhance reflexivity and potentially augment the 
PODWALKING

robustness of qualitative research (Author \& Other, 2006). Empirical openness via reflexivity offers ways to enhance transparency, and from an action research perspective, promotes ways to highlight the researcher's 'muddy' footprints.

Another reason to move beyond the dead researcher criterion is that in action research, the researchers are central to the inquiry process. Hence, the dead researcher stance is unattainable. The reflexivity of the interactive researcher may also be augmented by methods that move away from the static interview. In using digital technology and processes of engagement which mobile methods demand, the analysis of power, participation and the product of research are open to analysis beyond the framing of traditional interviews.

This article is focused on data generation through a project developed from the model of technical action research which Carr and Kemmis (1986) describe as projects initiated and led by researchers who bring their own rationale for the research to the context in which they facilitate practitioners to implement change. Our analysis explores the effectiveness of change and is intended to contribute to the research literature while encouraging practitioners to reflect upon their practice. This technical action research approach also drew on a 'practical' model which Carr and Kemmis (1986, p.203) describe as outside facilitators forming “...cooperative relationships with practitioners, helping them to articulate their own concerns, plan strategic action for change, monitor the problems and effects of changes and reflect upon the value and consequences of the change actually achieved...”. Collaboration and cooperation was central to the project as the research aimed to encourage the use and acceptance of digital technologies by social care professionals to undertake 
PODWALKING

(what became known as) Digital Life Story Work (DLSW) with adolescents living in state care. The DLSW approach is built on, and seeks to enhance, conventional therapeutic approaches designed to promote a sense of security in younger children living in state care through helping these children to construct life narratives (Ryan \& Walker, 2007). As researcher, the lead author collaborated with professionals and adolescents in the residential care field to drive and refine the DLSW techniques to engage adolescents in coherence enhancing dialogues via digital technologies (Author \& Author, 2013). Such requirements meant that the research process engaged participants (adolescents and residential staff members) and stakeholders (residential home and organizational managers) in planning, carrying out and reflecting upon implementation progress at various points in the project. In this respect the model of action research evolved into a more emancipatory action research process. In this process collaboration was of central importance in the joint exploration of individual and institutional barriers to transforming practice.

For Ross et al. (2009) the fluidity and spontaneity of action research with mobile methods and digital resources enabled the creation of "... research environments, encounters and exchanges, generating time and space for participants and researchers to co-generate and communicate meaningful understandings of everyday lives..." (p. 619). We expand upon these ideas by considering that when mobile methods are used they not only generate data about the research focus, but offer material about the research process and products. In this way, by positioning process and product within on-going research relationships, such elements become apparent and open to critical scrutiny. 
PODWALKING

For example, one of the key aspects of participatory action research is the requirement for researchers to explore the use of techniques that demonstrate how they have been participatory and how this may have influenced the process and outcomes of the research. The analysis of data derived from the entirety of participatory research processes is rare, and communicating the substance of this influence may be compromised by methods of publishing that do not complement multi-perspective multimodal data (Author, 2014). We suggest that mobile methods offer routes to embed new ways of gathering data within participatory research via everyday digital technologies, and that analysis of this data enables those outside the research process to become aware of the interactive researcher's footprints. With this goal in mind, this paper provides an overview of the mobile method we labelled podwalking. We then use a contextualized example to highlight how the iterative framework of podwalking promotes data collection, analysis and reflexivity across the action research process. We conclude by discussing how mobile methods allied with digital technologies are enabling long sought multivocality to be realized.

\section{Podwalking: process and iterative framework}

Podwalking is a mobile method underpinned by an action research ethos; its label reflects the nature of the activity as journey and product. Podwalking was created to be a component of DLSW. DLSW was developed through a PhD project supported by a University scholarship aimed at facilitating adolescents in residential care to achieve a stronger sense of self-coherence through harnessing everyday digital media as a meaningful, motivating and empowering way of engaging young people in Life Story Work. Life Story Work (LSW) is an established method for promoting self-coherence with children looked after by the state (Fahlberg, 1994; Rose \& 
PODWALKING

Philpot, 2005; Schofield \& Beek, 2006). LSW helps to make sense of experience through supporting reflections and managing feelings within a secure environment (Ryan \& Walker, 2007), but tends to be child focused and not routinely practiced with adolescents (Author, 2012). Indeed, Raws (2004) reported that work around identity stagnated with adolescents in residential care, despite practitioners acknowledging its importance. Practice research indicates that facilitating self-understanding assists in successful transition to adulthood (Gilligan, 2005; Rose \& Philpot, 2005; Ryan \& Walker, 2007; Schofield \& Beek, 2006; Stein \& Munro, 2008). As adolescence is a life transition which involves reflection on one's self and relationships (Erikson, 1982; Beckett, 2002; Galatzer-Levy, 2002; Coleman \& Hagell, 2007; Frydenberg, 2008), this reinforces the potential fruitfulness of LSW to create a strong sense of self which in turn helps young people relate with others, manage behavior, understand feelings and make beneficial decisions. DLSW is oriented around various technologies and techniques (mobile phone cameras, video cameras, audio recording devices, blogging, a bespoke website and podwalking). The use of technology to capture events, feelings and reflections offers not only a means of initial engagement but also a dynamic and dialogical way of managing, organizing and revising material.

Podwalking offers a process of engagement and the generation of narrative material through the sharing of a journey and the production of a definitive product at the end of the research process. In the DLSW project this end product was a podwalk DVD where the adolescent generated and edited a record of their journey, and burned this to a DVD to be kept by them. Podwalking involves four discrete phases: Preplanning and planning; Creating content; Editing and production; Premiere and time capsule (see Figure 1). These discrete yet interconnected phases provide an 
PODWALKING

iterative framework which maps onto the phases established in action research; plan, act, observe and reflect.

(Insert figure 1 here)

For the DLSW project pre-planning involves considering logistical and safeguarding issues at an institutional level prior to engaging adolescent participants in the project and planning of where, when and what content to create and how to create it. The creation of content is drawn from Ross et al's (2009) notion of a guided walk, in that podwalking positions participants as guides who are invited to share reflective narratives elicited when a participant visits places of personal importance. These visits are undertaken with an awareness of an immediate audience (in the DLSW project this was the researcher and an invited carer), and, through digital recording, of potential future audiences. Podwalking as conceived in the DLSW project meant that the process of the journey resulted in the creation of a specific DVD constructed by individual participants. This end product distances the podwalk from the more general idea of a guided walk and creates a vehicle to conclude the research, which helps to manage the researcher's exit from the field. By acknowledging that the podwalk aims to complete a specific product, participants and researchers establish an end point at which relationships can come to a close.

In the DLSW project the editing involved the discussion and selection of material to include in the podwalk product. Once satisfied with their editing and positioning of content, adolescents were invited to produce and burn their podwalk onto their podwalk DVD. The DVD created was the adolescents' to keep, helping to facilitate 
PODWALKING

reflections and the sharing of narratives in supportive relationships such as those with their current and future carers. The Premiere and time-capsule phase provided an end point to the research relationship, but leaves the possibility of adolescents reediting, re-working and re-presenting the material to future audiences and their personal reflection.

\section{Method}

\section{Participants}

The analysis presented draws upon a corpus of data from ten adolescent participants (six males, four females, Mage $=15.3$ years, age range: $14-18$ years) living in state care and 35 associated carer participants recruited from across four English residential care homes. The carers (ages not sought) are positioned as participants, as they were engaged at various points across the entirety of the action research process. Extracts presented for analysis were recorded during the lead author's visits to the homes. Of a total of 186 visits, 56 visits were identified as relating directly to the facilitation of podwalking episodes, (with the other visits being oriented around other elements of the project listed previously). The podwalking facilitation provided 36 hours of audio and audio-visual data obtained from a sample of 45 participants. Permissions were gained from relevant gatekeepers and continual informed consent sought with the assistance of Participant Information Clips (Author \& Author, 2011) and on-going conversations. Ethical clearance was gained from the University ethics committee and partner organizations' research governance processes. Issues around institutional policies and professional anxieties concerning access and use of digital technology and safeguarding needed to be negotiated and adolescents, carers and care providers were informed that data used for dissemination would be edited so their identity was concealed. 
PODWALKING

\section{Generating talk: the podwalk process}

In the context of the DLSW project, the role of the researcher was to introduce podwalking to care homes staff as a process to engage adolescents in sharing stories and creating an end product. Once agreement was gained from relevant gatekeepers and care home staff, pre-planning began. This element (the only one not to be recorded) involved conversations with staff to identify meaningful places and people adolescents may wish to visit. Discussions also took place regarding potentially sensitive places (such as those holding specifically difficult memories or associated with people prohibited from meeting the adolescents). Following such discussions podwalking was introduced to adolescents. Once informed consent was gained the digital recorder was turned on and the phased podwalk progressed in line with the framework set out in figure 1.

\section{Representing talk and clip preparation}

Audio elements of research process material and podwalk footage were transcribed using orthographic representations. Sections contingent to research aims were then transcribed using Jeffersonian transcription methods (Jefferson, 1984). For readers unfamiliar with the symbols used in the Jefferson transcription system please see appendix 1 . This method allowed the various modes in which data were recorded to be represented in ways that enabled subtle features of social exchanges to become available to analysis. This method also permitted supplementary non-verbal features to be noted. This aids the translation of multimodal data to the printed page for readers who are unable to access the selected audio-visual clips made available to reinforce analytical claims. Identifying verbal and visual data in the supplied supplementary material is redacted to ensure anonymity. 
PODWALKING

\section{Analysing talk}

Analysis focused upon the discursive work undertaken by adolescents, carers and the researcher since talk is the site in which power and identities are negotiated contested and enacted (Potter \& Wetherell, 1987). In line with this discursive psychological lens, the primary interest of the analysis is in talk across the phases of the research. It is recognized that interactional episodes unfold with specific individuals, within contexts nested in wider institutional systems. Therefore, this analysis also draws upon Goffman's (1959) dramaturgical approach, which provides a way to locate social performers and their performances in broader social contexts. For example, in podwalking for DLSW the 'planning phase' is embedded in the institutional domain in which the project interaction concerns the management of risk and the administrative demands of enabling the podwalk, while in the 'creating content' phase, interaction is more fluid and spontaneous.

\section{Analysis}

\section{Discerning researcher's footprints across participatory research}

Locating occasions of talk stimulated by the podwalk framework is undertaken with an appreciation that talk relating to power, ownership, relationships and audience transcended each phase and the situated relationships. The analysis demonstrates how the goal of producing the podwalk DVD facilitated participant's located meaning making which conventional interview methods may not apprehend.

\section{Pre-planning and planning: negotiating power}

Podwalking in the DLSW project aimed to empower adolescents to take control of the construction of autobiographical narratives in the context of supportive relationships, but the initial process was researcher led and situated in the context of 
PODWALKING

institutional power dynamics. Through the introduction of the podwalking framework and its attempts to engender empowerment, the analysis of data collected in this phase of the research was sensitized to power dynamics of the adolescent/researcher/carer relationships. Extract 1 is taken from an exchange which took place in the dining room of the Gateford Road home during the planning of Phil's podwalk. During the exchange Rose and June (staff), the researcher (R), and Phil (15) are present. The extract illustrates the way in which power shifts occurred, especially in the way in which professionals experienced taken for granted elements of emancipatory research processes.

Extract 1: The professional power shift

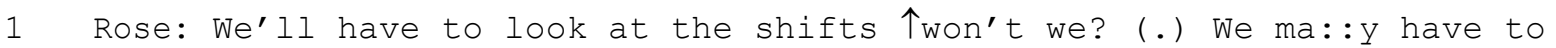

2 get someone else in=cos we'll be out a go: : : od (0.5) few hours

$3 \quad[$ won't we?]

4 R: [Yeah ] (1.0) Do [ you want]

5 June: [best to go] in the office(.)

6 R: Do you want to do [that $\uparrow$ Phil?]

7 Rose: [个Yeah we: :1l] go in the office

$8 \quad(0.9)$

9 R: Okay (.)

June's talk "[best to go] in the office" relocates the conversation from the living room to the office, and evidences how the logistics of planning the filming phase, and the power to plan, often became transferred to staff members. Rose's initial talk 
PODWALKING

positions Phil, and to some extent the researcher, as problem solving partners. In recruiting what Davis and Harré (1990) called interactive positioning, Rose's repeated use of "we" weakens institutional power differences inherent in their relationship. However while Rose's talk maintains an inclusive positioning, it also makes use of institutional terminology ("shifts") which risks excluding the other participants. The researcher begins to take up the opportunity for inclusion (line 4) to reinforce Phil's position as having choice. This intention is known through the role of an interactive researcher, in which the conversational experience can be accessed. Even without this specific knowledge, the discursive evidence shows the interruption from June with the direction to move into the office. Davies and Harré (1990:266) stated that positioning theory serves to: "...direct our attention to a process by which certain trains of consequences, intended or unintended, are set in motion." Here, both the process of relocation to a professional environment and the professional dominance of the talk follow a pattern in which the researcher's inquiry to Phil (line 6) was a consequence of the working up of an initial invitation to participate (line 4) being prematurely interrupted by June (line 5). Rose adopts a position of what Goffman (1959, p. 88) calls a team mate: “...someone whose dramaturgical cooperation one is dependent upon in fostering a given definition of the situation." Goffman (1959, p. 91) adopts the notion that people become performance team mates in developing a routine and that "Once the team's stand has been taken, all members, may be obliged to follow it." Rose and June take up a team role which is not easily countered.

Work diaries and carer duty documents are kept in offices of residential homes. These would be needed to discuss logistics of the podwalk but June's relocating 
PODWALKING

instruction undermines the position offered to Phil by Rose's initially inclusive talk and the researcher's attempt at inclusion. By relocating the dialogue to a part of the house entrenched with the institutionally based power, the potential of Phil's voice to be heard as an equal diminishes. June's interruption of the researcher's invitation to Phil adds to the strength of this appropriation of power. June's talk begins to remove some of the neutrality offered by the living room, but also in interrupting the researcher's second overt attempt to invite Phil to contribute, Rose (line 7) positions herself in coalition with June. Noticeable by its absence is Phil's voice. Though present, Phil is discursively silent. In the dialogue the professional shift, both in the control and site of the talk, closes down alternative positions for collaboration.

The excerpt evidences how digital material collected throughout the podwalk framework may illuminate negotiations preceding the beginning of conventional data collection. It also illustrates that opportunities for empowerment, like talk itself, are not stable but require constant management within individual and institutional dynamics. As with any other endeavor, participatory action research unfolds within discursive contexts, simultaneously creating and sustaining the concept of participation and negotiated power. Participatory research is constructed by researchers trained in the use of research methods and analysis, which manufacture outcomes that are congruent with the participatory ethos In analyzing the data from a participatory process we are therefore analyzing a social product in which we as researchers have a stake. While claiming an empowerment outlook, we demonstrate that interactions which aim to produce empowering practices are frequently unequal and can result in inhibiting the voice of some participants. 
PODWALKING

\section{Filming phase: empowerment via ownership}

A central aspect of adolescent generated podwalks was to stimulate a sense of control over the podwalking process and ownership of the materials produced. This idea of ownership is important in life story work, not only with young people but also in other context such as nursing home residents (Wills \& Day, 2008) and in learning disabilities (Meininger, 2006) as the LSW process places individuals' memories and experiences at the heart of a process in which they are recreated, reconfirmed or renegotiated. So for example, whether or not to participate in a podwalk was a personal preference and adolescent's choice of location for the podwalk was facilitated whenever possible. Participants were also encouraged to operate recording devices. Extract 2 and clip 1 (available at:

https://www.youtube.com/watch?v=M4V4tYuwkDc) are taken from Billie's podwalk. Unlike other content creation phases, only the researcher and Billie (15) were present during his filming. Extract 2 followed several unsuccessful attempts by the researcher to prompt Billie to operate the camcorder. The analysis illustrates the negotiations of ownership and the attempts to elicit engaged participant accounts.

Extract 2: Seizing control through the offer of a grab

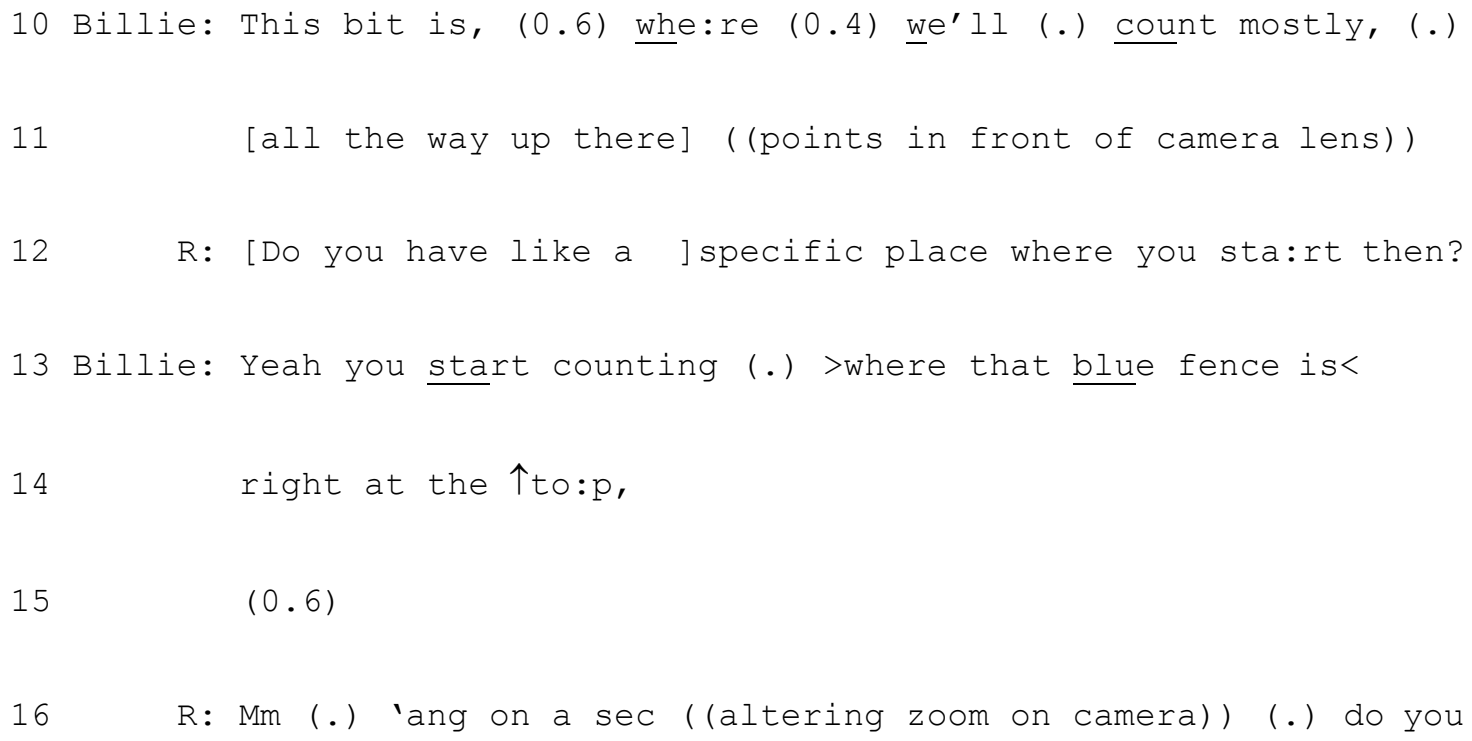




\section{PODWALKING}

19 Billie: $\uparrow$ Right at the to:p

21 Billie: [FOR GOD'S]=((taking camcorder )) =SAKE you're useless you are,

23 Billie: There's the bloody gate $\uparrow$ see that gate there [yeah]

$24 \quad \mathrm{R}$

26 Billie: That one (.) that's the one we:'ll go to,

36 Billie: =fly: :ing up 'e:re, yeah< (.) I was biking on this pavement >he 
PODWALKING

38

mate doing $\uparrow \uparrow$ doungnuts I thought he was going to $\uparrow \uparrow c r a s h$ into

$39 \quad[\uparrow m e$,

40 R: [Huh ] huh

The extract indicates an apparent inability of the researcher to perform the role of camera operator and audience by interrupting the account to request directional information (line 12). In responding, Billie directs the researcher as camera operator and answers his question (lines 13-14). His talk positions himself as director whilst maintaining the researcher's position as camera operator. Despite this, the researcher reoffers the position of camera operator to Billie, expounding a lack of mastery coupled with an invitation for Billie to take up his own position of authority through orientating the camera's lens. These are performed in the researcher's talk by stating his need to halt the account to find the focus of Billie's narrative (lines 1617). The researcher's repositioning is successful and results in Billie taking the role of camera operator. The repositioning talk featured two pauses, opportunities for Billie to take the position and associated power, rather than it being given. When this does not occur the researcher's talk becomes more directional "grab it?". Billie accepts the position of camera operator and accounts for his acceptance by positioning the researcher as incompetent, reinforced by the researcher's selfpositioning (lines 21-22). In this way Billie establishes engagement and control on his own terms.

This extract illustrates the complexities in power relationships, and the problematic positioning of researchers in giving voice to marginalized populations has been well documented (Mazzei \& Jackson, 2009). Spyrou (2011 p. 152) proposed that: 
PODWALKING

“...we need as researchers to become more aware of how children's voices are constantly constrained and shaped by multiple factors such as our own assumptions about children, our particular use of language, the institutional contexts in which we operate and the overall ideological and discursive climates which prevail”.

The episode demonstrates how the researcher encourages a 'grabbing' of the tools which enable the participants' voice to be heard ${ }^{1}$. In the extract, the point at which Billie begins to zoom back and hence assert his control over the camcorder is also the moment when his social performance becomes more assured. This sense of mastery is evidenced through a confident declaration: "cos we i:s clever" (line 30). In having grabbed the position of camera operator Billie changes the expressiveness of his talk. His account becomes more detailed, emotive and dynamic. In the narrative (beginning at line 33) his account starts to include additional detail. Though represented via text, the dynamic features of the exchange are articulated more fully via clip 1. Thus, in presenting this work, we also lend support to the rationale for considering mutlimodal publishing platforms (Author, 2014).

\section{Filming phase: The audience and account construction}

The places visited during content creation presented participants with stages upon which to re-enact experiences and reconstruct memories. Extract 3 and clip 2 (available at: https://www.youtube.com/watch?v=ZLDuX4-nl7s) 
PODWALKING

https://www.youtube.com/watch?v=ZLDuX4-nl7s are taken from Ivy's filming phase in which she was accompanied by the researcher and staff member Sam. This exchange involves Ivy (15), Sam and the researcher and illustrates how mobile methods permit the use of props but also how accounts produced are influenced by audience engagement.

Extract 3: The tough audience

42 Ivy: $\uparrow \uparrow$ That's the field I had my tenth bi:rthday party there, 


\section{PODWALKING}

57

58

59

60

61

62

63

64

65

66

67

68

69

70

71

72

73

74

75

76

$(0.8)$

Ivy: Ages ago: and all th-all the ma:rks in it my sister did, (.)

a:nd tha:t's (.) the (.) the Tga:te never used to be there (.)

but everythink else used to be, and 个number fou:r is my Mum's

mate Dia (.)[Diana] she lives 个there (.)

$\mathrm{R}: \quad[$ Yeah ]

Ivy: 个U:::m (.) <numbe: :::r (.) sixty seven,> (.) i:s (.) Mike's

old house th: :e number, (.) number one, (0.4) is Vicky's hou:se

$\mathrm{R}$ : Number [one] Vick:y?

Ivy: [No ] Number o:ne's Vicky number two is gay

Pa:ul's old (.) hou:se, (.) he used to live there with his mum

(.) you know gay 个Paul, (0.4) we're 个not mo:ving, so I don't

need my seatbelt on (.) 个you know gay Paul don't you Sam? (0.4)

yea:h you can talk you know (0.4) you don't need to (.) m:ess

about like a spaz

Sam: $>$ hhhhhh<=

$\mathrm{R}: \quad \quad={ }^{\circ}$ That's outrageo[us ini] $t^{\circ}=$

Sam :

[Not PC]

R: I can't believe it=

Ivy: =Right keep going now tbye old hou:se (.) my old bedroom's at 


\section{PODWALKING}

77

the back

78

$\mathrm{R}:$ Is it? $\uparrow(0.4)$ [what at] the fie:ld?

79

Ivy:

[Yea:h ]

Yeah (.) Go up, (.) slowly

(0.4) 'that's that's Maz's (.) sister's house (.) that's Mrs

81

Brown's house, >go slowly< that's Becky's house

Facilitated by the researcher Ivy develops her historical connection to place. She does this by working up knowledge of specific features and her relationship to characters linked to the scene. From a discursive perspective when an individual presents a memory, the act of remembering serves as evidence of 'truth' and remembering enabled participants to claim connections to place via constructing accounts of relationships and experiences (Edwards \& Middleton, 1986). In the context of this analysis, attention turns to how the narrative is disrupted as Sam's role as a disengaged audience emerges and curtails performance.

During her account Ivy speaks of others who inhabited the same place at the same point in time. In lines 68 and 69 Ivy seeks to recruit Sam to authenticate her account, to strengthen her social performance and with it her relationship to place. Sam does not take up this invitation. Motives for silence (such as a reluctance to endorse the homophobic epithet Ivy uses) are not at issue, but by not accepting Ivy's invitation the account under construction becomes damaged. In line 70 Ivy reissues this invitation. Again it fails. In an attempt to repair damage done by Sam, Ivy continues: "you don't need to (. )". After a brief pause lvy issues a parting insult distancing herself from attempts to recruit Sam (lines 70-71). Goffman's (1959, p.89) concept of social actors as team mates ("...it is just because he is part of the team that he can 
PODWALKING

cause this kind of trouble...") underlines why the discursive repair work was undertaken by Ivy. If Ivy had not attempted to position Sam as a team mate, the damage inflicted by Sam's silence would have been different. To remain silent when prompted is a powerful sign of disengagement. Ivy's stage position becomes untenable and she quickly issues an instruction to Sam as the car driver to leave the scene (line 76).

As this action begins to take effect Ivy gives her audience a final chance to save her performance: "my old bedroom's at the back". Responding to this statement the researcher attempts to co-construct the account and repair the performance. By using knowledge of the orientation of Ivy's old bedroom in relation to the site of her tenth birthday (lines 42-46), the researcher takes an engaged position, distancing himself from the disruptive teammate by demonstrating previous attentiveness. Ivy accepts the incentive to continue, however as visual elements of clip 2 illustrate, the car is moving away and the potential for elaboration is lost.

In reviewing this account and clip as situated interactive researcher, social actor, analyst and author, I (the first author) cannot claim to remember what I was thinking at the time. To do so would be misleading. As analyst in the now, I would suggest that in the role of researcher, I was invested and keen to re-engage Ivy in the sharing of the narrative and used her "old bedroom" scene to achieve this.

\section{Editing and production phase: meaning co-construction}

The editing and production phase invited adolescents to review, edit and select episodes to include on their DVD. This phase made negotiations about current meanings and power issues embedded in the process, especially those related to 
PODWALKING

the power of adolescents to designate staff positions, available for analysis. Extract 4, from the editing phase of Ivy's Podwalk, orientates around a section she labelled as 'Get out the way love'. This section recorded an everyday event, a pedestrian walking into the road in front of the car Ivy, Sam, and the researcher were in during filming. The researcher's response was captured and his remark 'Get out the way love' was rendered with his regional accent, atypical of the area where the research was undertaken. During this phase, the clip's meaning begins to be constructed and used by each contributor as a performative resource, a basis for the construction of social reality, of what the episode means for each individual involved.

Extract 4: Get out of the way love.

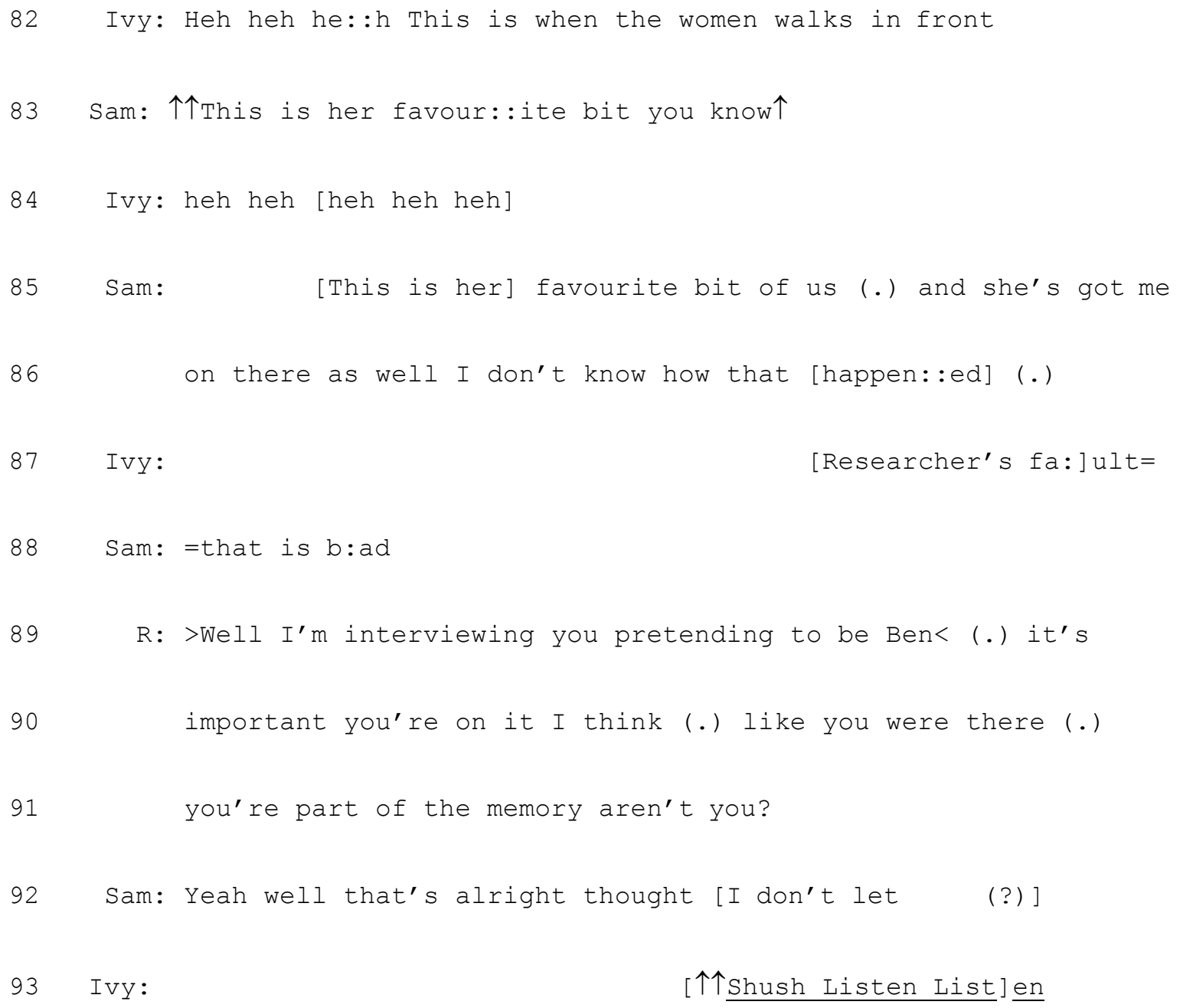


PODWALKING

The playing of this clip enabled Sam to work up a construction of the 'Get out the way love' section as Ivy's favorite. By virtue of Sam's repeated attempts to position this clip as Ivy's favorite, she too can take the privileged position of favored carer through her presence within it (line 85-86). The importance of this favorite position in the context of residential care is a valuable one, opening up a further dynamic of the research process. Ethnographic research conducted by Emond (2002) demonstrated that for adolescents, there can be a noticeable change in atmosphere when popular or unpopular members of staff are on shift. Being seen as a preferred member of staff is associated with being treated more favorably than those perceived as unpopular (Emond, 2002). In this way gains made through working up this podwalk section as Ivy's favorite potentially benefits Sam's relationship with Ivy, other adolescents and colleagues alike. Sam is initially reluctant to be included, but the researcher encourages her presence (lines 89-91). This renewed stake is illustrated by extract 5 taken moments after Ivy had dragged and dropped the clip onto the final podwalk storyboard with Sam expressing concern that the clip was not included. This exchange offers an insight into the power of researchers to shape inclusion and of adolescents to position care workers (and other professionals), as well as how professional discourse with adolescents is embedded in relationship management.

Extract 5: She hasn't put it in 
PODWALKING

98

Ivy: $\uparrow \uparrow$ It is watch it watch it (.) $\uparrow$ watch it (.) heh heh

Ivy's talk within the editing illustrates her enjoyment in reviewing the clip. The clip allowed her to revisit the playful social performances during the filming and to attend to the associated relationships. In this way the inclusion of this narrative in the podwalk alongside other more poignant ones provides a source for the re-telling of the events from the filming and the relationships which unfolded during recording. Sam's animated interest in editing contrasts with her involvement in the content collecting phase. In participatory research levels of participation may vary and the influence of individuals may be displayed in both passive (unintentional) ways and through active (intentional) behavior. The analysis of the editing extracts demonstrates this dynamic process. In extracts 4 and 5 , Ivy does not challenge the professional account; this may be seen as passive acceptance. However the editing takes place through the focus on a situation in which Sam's lack of co-operation is foregrounded. The evident enthusiasm with which Sam engages in the editing process, it could be argued, may be related to her earlier reticence. Thus the editing process repairs the relationships of the content collection phase and Ivy's active camaraderie facilitates this repair. Both of these phases are made available for critical analysis via the podwalk framework.

\section{Premiere and time-capsule phase: exit relationships and on-going reflections}

The ending of research relationships is something participatory researchers need to be sensitive to. As a former residential worker I (the first Author) was aware that adolescents living in state care do not always get the opportunity to create relationship endings. This phase enabled a specific endpoint to be established, but 
PODWALKING

also created the possibility of accessing talk occurring traditionally after recording equipment is off. Extract 6 was recorded during the first viewing of Nikki's podwalk DVD. The viewing was undertaken the home's living room with the researcher and fellow residential home resident lvy present.

\section{Extract 6: On-going Reflection}

107 Nikki: $\uparrow$ I wonder how I met Cal?

$108 \quad(0.8)$

$$
\mathrm{R}: \text { Who's } \uparrow \mathrm{Cal} \text { ? }
$$

110 Nikki: My ex boyfrie:nd,

111 R: At school? (.)

112 Nikki: 个What?

113 R: At school? (.)

114 Nikki: No (.) He used to live up ere (.) He still does he lives with

119 Nikki: [huh huh huh] 个No (.) I don't know $\uparrow$ (0.3)

120 R: Maybe your eye meet across the slide

121 Ivy: huh huh

122 R: huh huh 


\section{PODWALKING}

123 Ivy: huh

124 Nikki: No I met him

$125 \quad(3.0)$

126 Ivy: O:: : I see

127 R: Huh huh (0.8) huh brilliant Ivy

128 Ivy: huh

$129 \mathrm{R}$ : You need to get back to school girl am telling y(hh) ou $\uparrow$

130 Nikki: O:h I met 'im cos (.) Ja:ke was wal- walking with to the pub (.)

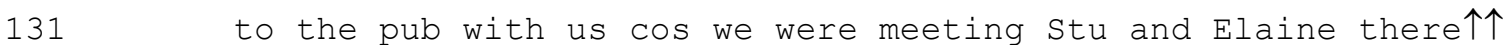

$132 \quad \mathrm{R}: \mathrm{A}: \mathrm{r}$

133 Nikki: And Ja:ke's > 个mum and dad< (.) a: : :nd, that's how I met him I

134 met him there

135 R: And Jake wa: :s (.) your frie:nd?

136 Nikki: Yeah

$137 \mathrm{R}:{ }^{\circ}$ oh right $^{\circ}$

138 Nikki: ${ }^{\circ}$ he's special ${ }^{\circ}$ (?) (.) and Cal was just there (.) I ${ }^{\circ} \downarrow$ can't

139 remember ${ }^{\circ}$

140 R: So Cal was Jake's mate?

141 Ivy: [ (?) ]

142 Nikki: [Yeah] 
PODWALKING

The extract illustrates the process of co-construction in this phase and the nature of on-going reflective dialogues. In the first instance Nikki's reflective question invites audience members to assist in the constructing of its answer. This reflective question was prompted by interactions edited and represented on her podwalk DVD. During Nikki's filming phase she chose to revisit a park. Whilst here Jim, Nikki's invited guest, enquired whom she used to hang out with at the park. This caused Nikki to list the names of former friends.

In Nikki's premiere, her response to watching herself list her friends triggered the reflective question: " $\uparrow$ I wonder how I met Cal?". In an attempt to assist in the construction and sharing of this reflective narrative the facilitative power of audience members is again highlighted. By ruling out possibilities of where they met (line 124), Nikki is able to furnish the account being worked up with more details: "He used to live up ere (.) He still does". The reflective question originally shared pertaining to a gap in the narrative is resolved via her friendship with Jake and his association with Cal. Nikki states she met Cal through a mutual friend Jake, whilst they were on their way to meet her former friend's parents and her former carers. The reflective performance allows a further development of the initial narrative. Indeed such rehearsal of events may continue each time the podwalk is replayed. This possibility illustrates the complexities and multi-layered nature of the phased podwalk process and how the approach can access and manage different streams of qualitative enquiry.

The giving of a DVD to participants and reviewing these with participants enabled the podwalk framework to collect additional data as illustrated by extract 6 . The social 
PODWALKING

act of giving the DVD also enabled the closing of research relationships and the researcher's exit from the field (Author \& Author, 2013). Commonly in Western cultures when leaving an establishment in which an individual has become involved for a significant period or a period of significance, this is marked by the ritual of giving and/or receiving gifts. As research product, the DVD fulfilled this purpose and acted as a relationship memento.

\section{Discussion}

Those who engage in constructionist and relational research recognize the discursive nature of inquiry. Gergen (1999, p.115) called for more "...forms of investigation that help us to reflect critically and appreciatively on our condition, our traditions, institutions, and relationships." We have shown that in using digital recordings, the podwalk framework enabled data to be collected which cuts across iterative research processes. In so doing, the framework created the potential for analytical considerations to be applied to data collected during and beyond typical research techniques and brought the research relationships into sharper focus. The podwalking approach can therefore create an investigative ethos which helps researchers appreciate and evidence the dialogical qualities within the coconstruction of knowledge. While this relational perspective acknowledges the dynamic nature of qualitative investigation, it also alludes to but does not address inequalities of power which are inherent both in the research process and in the development of a research narrative.

When assuming an interactive, participatory and action oriented approach, the researcher's presence, relational style and scholarly assumptions are all played out 
PODWALKING

throughout the research cycle. Even as they hold themselves to a more fully and self-consciously egalitarian standard than traditional researchers, the complexities of empowerment and representation rise to the surface. Strategies to explore power dynamics often take the form of reflexive approaches to reporting. This is essential when interactive researchers step inside the enquiry process, and double the opportunities to explore generated discourse, through both the interpretation of data and reflection upon the dynamics of data generation (O'Rouke \& Pitt, 2007). The use of discursive analysis to examine interactional dynamics in research facilitates reflexivity (Author \& Other, 2006). In qualitative inquiry power differences need not only to be recognized, but to be managed and in the coupling of action research with discursive analysis and mobile methods enabled by digital technology the disclosure of this management is facilitated in a clear, open and accessible manner. While power between researchers and researched may always be uneven, the podwalking framework enabled critical reflexive attention to be focused on the degree to which power is shared and the obstacles to partnership, as well as on techniques to enhance rapport and alliances.

The podwalk framework maps out a system for the recording and systematically exploring interaction, the power and the negotiation of meanings by an involved and very much 'alive' researcher. The framework represents an under-construction first step into a movement which, it is hoped, will enable a fuller critical reflection in the pursuit of the social changes for which action researchers strive. The difficulty of rendering multimodal data into print also adds weight to the call for publishing to look towards enhanced or multimodal journal articles (Author, 2014). In the 1980s and 1990s the place of dialogical or multivocal forms of research was being 
PODWALKING

conceptualized (Stainton Rogers, Stenner, Gleesen \& Stainton Rogers, 1995). The process of mobile methods allied with digital technologies is enabling multivocality to be realized in an even more complete way. Despite the constraints of traditional dissemination, the research process can become more open to critical appraisal through these efforts to contextualize that process. This framework, therefore, enables a more complete narrative of research projects than those based on static approaches such as the research interview.

The podwalking process also has implications for quality appraisal. In discussing the focus of naturalistic inquiry Lincoln and Guba (1985) argue that it is the participants themselves who are best able to understand the meanings in data. They state that: “...respondents are in a better position to interpret the complex mutual interactions ... because respondents can best understand and interpret the influence of local value patterns" (Lincoln \& Guba, 1985, p.41). This distinctive positioning of the participants' perspectives leads to quality checks such as member checking in which researchers return to participants with data interpretation for confirmation or to refine understanding through gathering more data. Such an approach to discerning quality has been criticized as providing a one dimensional approach to understanding a process which has a dialogical quality through interviews which construct data (Harvey, 2015). The analysis of podwalking demonstrates, and renders open to analysis, the place of the researcher as both participant and stakeholder. Following from this, participatory inquiry assumes that the coconstruction between researcher and respondents gives the best view of the world as fashioned through a specific investigation, and the way in which this co- 
PODWALKING

construction has developed through negotiated stages of research creates a further thread to the research tapestry. 
PODWALKING

\section{References}

Anderson, J. (2004). Talking Whilst Walking: A Geographical Archaeology of Knowledge, Area, 36, 254-61. doi: 10.1111/j.0004-0894.2004.00222.x

Author, A. A., \& Author, B. B. (2011). Details withheld for peer review.

Author, A. A., \& Author, B. B. (2013). Details withheld for peer review.

Author, B. B. \& Other, A. (2006). Details withheld for peer review.

Author, A. A. (2012). Details withheld for peer review.

Author. A. A. (2014). Details withheld for peer review.

Beckett, C. (2002) Human Growth and Development. London: Sage.

Büscher, M. \& Urry, J. (2009). Mobile Methods and the Empirical. European Journal of Social Theory, 12, 99-116. doi: 10.1177/1368431008099642

Coleman J. \& Hagell A. (2007). Introduction. In J. Coleman and A. Hagell (Eds) Adolescence, Risk and Resilience: Against the Odds. Chichester: Wiley.

Davies, B. \& Harré, R. (1990). Positioning: The discursive production of selves. Journal for the Theory of Social Behaviour, 20, 43-63. doi: 10.1111/j.14685914.1990.tb00174.x.

Edwards, D. \& Middleton, D. (1986). Joint remembering: Constructing an account of shared experience through conversational discourse. Discourse Processes, 9, 423459. doi:10.1080/01638538609544651.

Emond, R. (2002). Understanding the resident group. Scottish Journal of Residential Child Care. 9, 30-40. 
PODWALKING

Erikson, E. H. (1982). The Life cycle completed: A Review. New York: Norton.

Fahlberg, V. (1994). A Child's Journey through Placement. London: British Agencies for Adoption and Fostering, (BAAF).

Frydenberg, E. (2008). Adolescent Coping: Advances in Theory, Research and Practice. London: Routledge.

Galatzer-Levy, R. M. (2002). Created in others' eyes. Adolescent Psychiatry: Development and Clinical Studies (26) 43-72.

Gergen, K. J. (1999). An invitation to social construction. London: Sage.

Gilligan, R. (2005). Resilience and Residential Care for Children and Young People. In D. Crimmens and I. Milligan, I. (Eds) Facing Forward - Residential Child Care in the 21st Century. Lyme Regis: Russell House Publishing.

Goffman, E. (1959). The Presentation of self in everyday life. New York: Anchor Books.

Harvey, L. (2015). Beyond member-checking: a dialogic approach to the research interview. International Journal of Research and Method in Education, 38(1), 23-38. doi:10.1080/1743727X.2014.914487

Holstein, J. A. \& Gubrium, J. F. (2003). Inside Interviewing: New Lenses, New Concerns. Thousand Oaks, CA: Sage.

Jefferson, G. (1984). Transcript notation. In J. M. Atkinson J \& J. Heritage (Eds.), Structures of social action: Studies in conversation analysis. (pp.346-69). Cambridge: Cambridge University Press. 
PODWALKING

Lincoln, Y. S. \& Guba, E. G. (1985). Naturalistic inquiry. Beverly Hills, CA: Sage.

Mazzei, L. \& Jackson, A. Y. (2009). Introduction: The limit of voice. In: Jackson A and Mazzei L (eds) Voice in Qualitative Inquiry: Challenging Conventional, Interpretive, and Critical Conceptions in Qualitative Research. London and New York: Routledge, 1-13.

McNiff, J. (2013). Action Research: Principles and practice. New York: Routledge.

Meininger, H. (2006). Narrating, writing, reading: life story work as an aid to (self) advocacy. British Journal of Learning Disabilities, 34(3), 181-188.

O'Rourke, B. K. \& Pitt, M. (2007). Using the Technology of the Confessional as an Analytical Resource: Four Analytical Stances Towards Research Interviews in Discourse Analysis [58 paragraphs]. Forum Qualitative Sozialforschung/Forum: Qualitative Social Research, 8, Art. 3, http://nbn-resolving.de/urn:nbn:de:0114$\underline{\text { fqs070238 }}$

Pink, S. (2007). Walking with video. Visual Studies, 22, 240-252. doi: $10.1080 / 14725860701657142$

Potter, J. \& Hepburn, A. (2005). Qualitative interviews in psychology: Problems and possibilities. Qualitative Research in Psychology, 2, 38-55. Doi: 10.1191/1478088705qp045oa

Potter, J. \& Wetherell, M. (1987). Discourse and social psychology: Beyond attitudes and behaviour. London: Sage.

Potter, J. (2002). Two kinds of natural. Discourse Studies, 4, 539-542. doi: $10.1177 / 14614456020040040901$ 
PODWALKING

Raws, P. (2004). Building a Future: an evaluation of the process and outcomes of services to young people in planned residential care within Durham Social Services childrens' homes. Social Work Research and Development Unit, University of York. http://www.york.ac.uk/inst/swrdu/Publications/Building a Future.pdf

Rose R. \& Philpot T, (2005). The Child's Own Story Life story work with traumatised children. London: Jessica Kingsley Publishers.

Ross, N.J., Renold, E., Holland, S., \& Hillman, A. (2009). Moving stories: Using mobile methods to explore the everyday lives of young people in public care. Qualitative Research, 9, 605-23. doi: 10.1177/1468794109343629

Roulston, K. (2010). Considering quality in qualitative interviewing. Qualitative Research, 10, 199-228. doi: 10.1177/1468794109356739

Ryan, T. \& Walker, R. (2003). Life Story Work: A practical guide to helping children understand their past (second edition), London: British Agencies for Adoption and Fostering. (BAAF)

Ryan T. \& Walker R. (2007) Life Story Work. London: British Agencies for Adoption and Fostering, (BAAF).

Schofield G. \& Beek M. (2005). Risk and resilience in long-term foster-care. British Journal of Social Work 35(8) 1283-1301.

Schofield, G. \& Beek, M. (2006). Attachment Handbook for Foster Care and Adoption. London: British Agencies for Adoption and Fostering, (BAAF).

Sheller, M. \& Urry, J. (2006). The new mobilities paradigm', Environment and Planning, 38, 207-26. 
PODWALKING

Spyrou, S. (2011). The limits of children's voices: From authenticity to critical, reflexive representation. Childhood, 18(2), 151-165. doi:10.1177/0907568210387834

Stainton Rogers, R., Stenner, P., Gleesen, K., \& Stainton Rogers, W. (1995). Social Psychology: A Critical Agenda. Polity Press, Cambridge.

Stein, M. \& Munro, E. R. (2008). Young People's Transitions from Care to Adulthood: International Research and Practice. London: Jessica Kingsley Publishers.

Stringer, E.T. (2007). Action Research (Third Edition). London: Sage Publication

Weiser, M. (1991). The computer for the 21st century. Scientific American, 265, 3, 94-104

Wills, T., \& Day, M. R. (2008). Valuing the person's story: Use of life story books in a continuing care setting. Clinical Interventions in Aging, 3(3), 547-552. 


\section{Appendix 1}

\section{Jefferson Transcription System}

[ ] Square brackets mark the start and end of overlapping speech. They are aligned to mark the precise position of overlap.

$\uparrow \downarrow \quad$ Vertical arrows precede marked pitch movement, over and above normal rhythms of speech. They are used for notable changes in pitch beyond those represented by stops, commas and question marks.

Underlining indicates emphasis; the extent of underlining within individual words locates emphasis and also indicates how heavy it is.

CAPITALS mark speech that is hearably louder than surrounding speech. This is beyond the increase in volume that comes as a by product of emphasis.

`^ 1 know it, $\quad$ 'degree' signs enclose quieter speech.

that's $r^{*}$ ight. Asterisks precede a 'squeaky' vocal delivery.

A micropause, hearable but too short to measure.

Numbers in round brackets measure pauses in seconds (in this case, 4 tenths of a second). If they are not part of a particular speaker's talk they should be on a new line. If in doubt use a new line.

she wa::nted Colons show lengthening of a word the more colons, the more elongation.

Yeh, 'Continuation' marker, speaker has not finished; marked by fall-rise or weak rising intonation.

y'know? Question marks signal stronger, 'questioning' intonation, irrespective of grammar.

Yeh. $\quad$ Full stops mark falling, stopping intonation ('final contour'), irrespective of grammar, and not necessarily followed by a pause.

bu-u- $\quad$ hyphens mark a cut-off of the preceding sound.

>he said $<\quad$ 'greater than' and 'lesser than' signs enclose speech with is faster than usual and are used the other way round for slower talk.

solid.=We had 'Equals' signs mark continuous talk between speakers, with no interval.

((shrill)) Double brackets mark comments from the transcriber, e.g. about features of context or delivery.

Appendix adapted from www-staff.lboro.ac.uk/ ssah2/transcription/transcription.htm 